\title{
DISTRICT WISE ANALYSIS OF COVID-19 PANDEMIC TRENDS DURING SECOND WAVE IN THE STATE ANDHRA PRADESH, INDIA USING SEIR-RGS MODEL
}

\author{
MSLB Subrahmanyam \\ Head-Imaging \& Algorithm Practices \\ Srikari Impetus solutions Pvt Ltd, Hyderabad, India
}

\begin{abstract}
Andhra Pradesh is one of the south Indian states in India and having 13 districts. This is one of the most Covid-19 effected state in India during first and second waves. In India district is the major administrative block for implementing government policies and schemes under control of district collector. So, estimating or forecasting trends in district level more important than state wise or entire country wise. In this paper we are proposing Susceptible, Exposed, Infected and Recovered - Regression and Grid Search (SEIR-RGS) model for analyzing Covid -19 district wise trends during second wave. The SEIR-RGS, initially collects daily wise covid data for each district from Department of Health, medical and family welfare, AP and estimates the model parameters like contact rate, incubation rate and recovery rate. To calculate recovery rate the proposed model uses regression technique between daily active cases vs cumulative recoveries. The present model uses two phases for estimating contact rate and incubation rate using grid search approach. After that the proposed method calculates the infectious period, incubation period and basic reproduction of infection in all 13 districts to analyze trends in the state during second wave and also to predict possibility of third wave in each district.
\end{abstract}

Keywords - Andhra Pradesh, SEIR, contact rate, incubation period, infectious period, regression, grid search

\section{INTRODUCTION}

At present entire world suffering from corona virus as a pandemic. Generally, viruses infect people with varying abilities. This virus initially detected in chain Wuhan lab in the end of December 2019. This outbreak entered into different waves and effected millions of the people globally. To reduce the effect of covid - 19 outbreak different counties took different strategies to minimize transmission of this pandemic like imposing lockdowns, face masking, social distancing, frequent handwash, restriction on international transports etc.

\author{
Vajjha Hem Kumar \\ Founder and Chief Architect \\ Srikari Impetus solutions Pvt Ltd, Hyderabad, India
}

India is one of the Asian countries which has huge number of populations nearly 134 crores people. In the first wave, government of India initially took lot of precautionary steps by imposing country wide lockdown to reduce outbreak of the corona pandemic. This decision helped for so many people's lives. Of course, effected on Indian GDP and also effected mainly on daily wage peoples. Due to this government started different unlock strategies in the phase wise to improve the Indian economy and allow the people to start their routine works. Later because of Kumbh mela, different elections in different states this pandemic entered into second wave and effected millions of people lives and families. As of now $3,34,47,010$ (three cores thirty-four lacs forty sever thousand and ten) people, 3,26,64,351(three cores twenty-six lacs sixtyfour three hundred and fifty-one) people and 4,44,869(four lac forty-four thousand eight hundred and sixty-nine) people infected, recovered and died with this virus respectively [32] till now. Now we are in almost end of second wave.

Andhra Pradesh is one of the south Indian states in India. Telangana, Karnataka, Tamil Nādu, Chhattisgarh and Orissa are bordering states of AP and its population around nine Crores. Agriculture is the major economy of the people in this state. More than 62 percent people depends on agriculture. This state can be divided into two regions namely coastal Andhra and Rayalaseema. Out of 13 districts nine districts comes under coastal Andhra and remining four districts comes under Rayalaseema. Uttara Andhra is another region in this state. Srikakulam, Vizianagaram and Visakhapatnam comes under in this region. In this state majority of the people prefer to migrate to other places for better employment or better livelihood. Initially very, few cases recorded in both first and second waves. But due to lockdown or micro contaminants in various places migrated people prefer to come back to their native place. Because of this reason covid -19 transmitted to even very remote places in the state and more people infected than expected. This is one of most covid effected state in India. During first wave 8,85,005(eight lac eighty-five thousand and five) people infected from Covid-19 and totally $99.05 \%(8,76,609)$ people recovered from this pandemic. In 


\section{International Journal of Engineering Applied Sciences and Technology, 2021 \\ Vol. 6, Issue 5, ISSN No. 2455-2143, Pages 273-285 \\ Published Online September 2021 in IJEAST (http://www.ijeast.com)}

the second wave $11,49,453$ (eleven lac forty-nine thousand four hundred and fifty-three) people infected and 98.23 percent (1129135) people recovered from this pandemic. 7,154 (seven thousand one hundred fifty-four) and 6907 (six thousand nine hundred and seven only) people lost their life in the first and second wave respectively.

The present model collected daily covid cases information of each 13 districts from Department of Health, medical and family welfare daily bulletin [31] and estimates the trends of all thirteen districts during second wave from 12-2-21 to 18-09-2021 i.e., totally 230 days. This department provides the detailed information about the covid infection among people of Andhra Pradesh district wise. This data contains the very detail information about the positives last 24 hours, Total positives, Total active cases, Total recovered and total deceased daily wise. And also provides the total number of samples tested for the disease on the current day. The present model uses SEIR model for forecasting or predicting covid cases. This model calculates model parameters using regression and grid search method mechanism. The proposed model estimates the contact $\operatorname{rate}(\beta)$ i.e., likelihood of new infections, incubation rate $(\varepsilon)$, recovery rate $(\gamma)$ and basic reproduction $\left(\mathrm{R}_{0}\right)$ of each district in the state of AP. From these parameters we can estimate Infectious period, incubation period and average basic reproduction $\left(\mathrm{R}_{0}\right)$ of each district in this state.

Currently so many papers available in the literature [1 - 29, 33-36] for modeling epidemics. In $4,9,10,11,12,13,14,15,20,21,22.23$ ] authors used SEIR model for predicting and estimating model parameters. Some authors $\left[\begin{array}{llllll}16 & 18 & 21 & 34 & 35 & 36\end{array}\right]$ used artificial intelligence, machine learning and deep learning techniques to estimate covid -19 trends. Authors in [ $\left.\begin{array}{llll}24 & 25 & 26 & 27\end{array}\right]$ used SIR model for predicting parameters while in [28 29] authors used SAIR model. In [6] authors presented mathematics of infectious disease. In 1927, William Ogilvy Kermack and A. G. McKendrick [7] introduced SIR (susceptible, Infected, and removed) mathematical model for analyzing the epidemics. Gaurav Goswamia[2] et. al. reconstructed effect contact rate of Covid. [8] addresses the asymptomatic cases of pandemics. In [1] authors proposed SUTRA model with addressing asymptomatic patients. Taarak Rapolu et al [4] used Time dependent SEIR model for transmission dynamics of covid. In [8] modified SEIR model for prediction of covid - 19 proposed. Bogdan Marincaa et at.[10] used Optimal Auxiliary Functions Method (OAFM) for solving nonlinear SEIR model dynamics. Using vaccination and isolation factors Suwardi Annas et al [11] proposed covid spread in Indonesia. This paper [12] analyzes India and Brazil as case study for SEIR model. Multi-stage SEIR model used in [13] to predict new cases before and after lockdown in KSA. Analytical solution for SEIR model described in [14] and via asymptotic approximation for analytic solution provided in [15]. Time dependent Deep learning-based prediction provided in [16].
Xinhe Zhu et at. [17] presented Extended Kalman filter-based model for Covid -19. In [18] authors analyzed impact of coronavirus on various countries using machine learning techniques. Hybrid model using fuzzy techniques for predicting infected and death people in India presented in [19]. Trace and isolate approach to control the infection transmission rate and reduce the of death rates are discussed in [20]. In [21] used AI model in non-Wuhan areas with the help of trends in Wuhan. Syafruddin et al [22] used SEIR model on dengue fever for the country Malaysia. In [23] authors applied dynamic SEIR model for Saudi Arabia real time Covid data. In [24] Manuel De la Sen et al. described SIR model using two parameters Malthusian and carrying capacity. Saad Awadh Alanazi [25] et al. used SIR model in smart health care system using advised techniques. Community based SIR model proposed in [26]. Adaptive based SIR model proposed in [27]. In [28] authors proposed social network based SAIR model on Wuhan data. In [29] authors analyzed SAIR model based on asymptomatic infection spread. In [34] authors presented machine learning based time series analysis of COVID 19 disease in India. Classification of covid and non-covid patients using Deep neural network model using lung $x$ ray images provided in [36].

The rest of the paper is organized as follows Section II contains the description of proposed method. Section III contains experimental results and conclusions are given in Section IV

\section{PROPOSED AlgorithM}

The proposed model divides the population under consideration into four compartment namely susceptible, exposed, infectious and removed. The first compartment I,e. susceptible represents the fraction of people who can be able to transmit the disease. The second compartment i.e Exposed represents the fraction of people whose body host for infection but not able to transmit to others. The third compartment i.e Infectious represents the fraction of people who are infected with the disease. The fourth compartment contains the fraction of people who recovered from the disease.

Let $\mathrm{t}$ be the time variable and $\mathrm{N}$ be the size of population Let $\mathrm{S}(\mathrm{t}), \mathrm{E}(\mathrm{t}), \mathrm{I}(\mathrm{t})$ and $\mathrm{R}(\mathrm{t})$ represents the susceptible, exposed, Infected and recovered respectively at time $\mathrm{t}$ as shown in Fig 1. Suppose all component values divided by $\mathrm{N}$ then these values lie between 0 and 1 .

So $S(t)+E(t)+I(t)+R(t)=1$

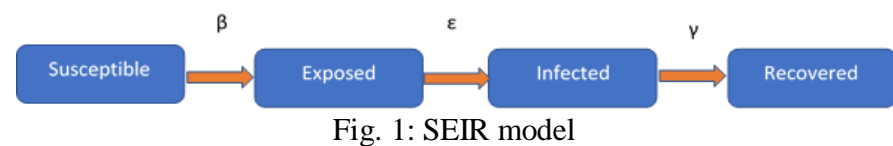

The following four differential equations represents migration of people from one compartment to another compartment with 


\section{International Journal of Engineering Applied Sciences and Technology, 2021 \\ Vol. 6, Issue 5, ISSN No. 2455-2143, Pages 273-285 \\ Published Online September 2021 in IJEAST (http://www.ijeast.com)}

time variable $t$. in this equation $\beta, \varepsilon$, and $\gamma$ represents contact rate, incubation rate and infection rate respectively. These parameters relate the model differential equations.

$$
\begin{aligned}
& \frac{d(T)}{d t}=-\beta * S(t) * I(t) \\
& \frac{d E(t)}{d t}=\beta * S(t) * I(t)-\varepsilon * E \\
& \frac{d I(t))}{d t}=\varepsilon * E-\gamma * I(t) \\
& \frac{d R(t)}{d t}=\gamma * I(t)
\end{aligned}
$$

In discrete form we can write as

$$
\begin{aligned}
& \mathrm{S}(\mathrm{t}+1)=\mathrm{S}(\mathrm{t})-\beta * \mathrm{~S}(\mathrm{t}) * I(\mathrm{t}) \\
& \mathrm{E}(\mathrm{t}+1)=\mathrm{E}(\mathrm{t})+\beta * \mathrm{~S}(\mathrm{t}) * I(\mathrm{t})-\varepsilon * E \\
& \mathrm{I}(\mathrm{t}+1)=\mathrm{I}(\mathrm{t})+\varepsilon * E-\gamma * I(\mathrm{t}) \\
& \mathrm{R}(\mathrm{t}+1)=\mathrm{R}(\mathrm{t})+\gamma * I(\mathrm{t})
\end{aligned}
$$

The proposed method uses the following initial conditions $\mathrm{E}(0)=1 / \mathrm{N}, \mathrm{I}(0)=0$ and $\mathrm{R}(0)=0$

So $S(0)=1-E(0)-I(0)-R(0)$

The proposed method for estimating contact rate, incubation rate and recovery rate using SEIR contains the following steps. The block diagram of proposed SEIR-RGS model given in Fig 2.

Step 1: the proposed method initially collects daily covid cases from the Department of Health, medical and family welfare daily bulletin [31] from 1-2-2021 to 18-09-2021. This data contains the cumulative daily infections, active infections, cumulative recoveries, and deaths respectively.

Step 2: calculate seven days average value for each active infection. Let us say $\mathrm{I}_{\text {avg }}$

Step 3: To calculate model parameters i.e., $\beta, \varepsilon$ and $\gamma$ the proposed method uses following procedure.

\section{Estimating $\gamma$ :}

The proposed method estimates the $\gamma$ value from the two time series data i.e., daily active cases and cumulative recoveries provided by Department of Health, medical and family welfare daily bulletin, AP [31].

From equation 5 we have

$$
\frac{d R(t)}{d t}=\gamma * I(t)
$$

It can be written as

$$
\begin{aligned}
R(t+T)-R(t) & =\gamma * \int_{t}^{T} I(s) d s \\
& \text { Where T is fixed time width. }
\end{aligned}
$$

Now generate two vectors $\{R(t+T)-R(t)\}$ and $\{\mathrm{I}(\mathrm{t})\}$ for various values of $t$ using two time series data i.e., daily active infections and cumulative recoveries respectively provided by Department of Health, medical and family welfare AP [31]. Finally, this paper estimates gamma value by fitting best line [33] passing through origin and through these vectors using equation. The slope of this line gives the gamma value. This paper considers $\mathrm{T}$ as 7 days.

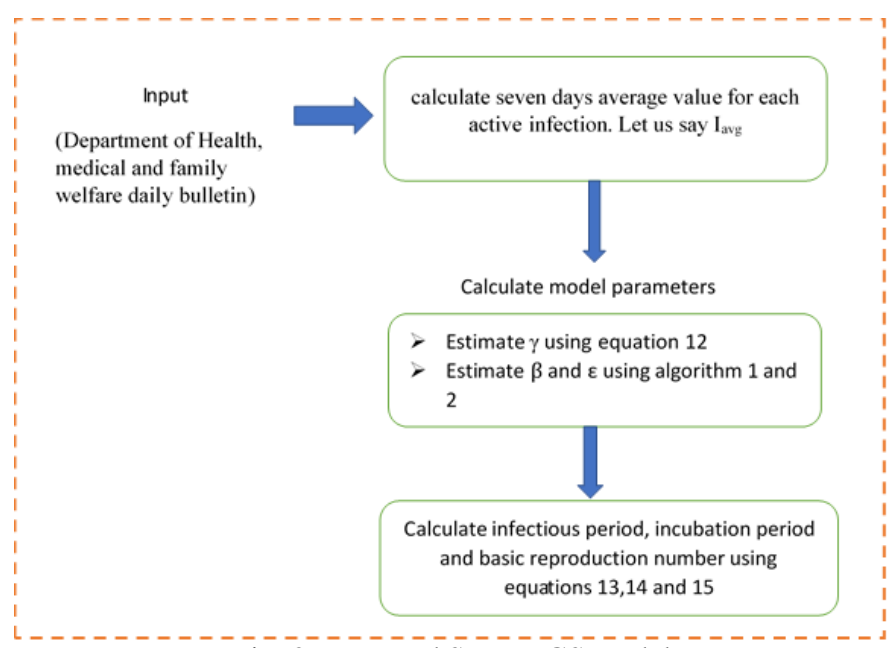

Fig. 2: Proposed SEIR-RGS model

Estimating $\beta$ and $\varepsilon$ :

The proposed method uses grid search method for estimating these parameters.

Grid search method initially identifies all possible range of values for each parameter. After that arrange these values into discrete grid and then calculates the model values from each combination of values in the grid. The optimal value of these combination of parameters gives the final solution.

The proposed algorithm uses the following range of values for each parameter

$\beta$ in the range between 0.1 and 0.5 with 0.001 increment i.e., transmission rate between 2 and 10

$\varepsilon$ in the range between 0.1 and 0.5 with 0.001 increment i.e., incubation rate between 2 and 10 days

The proposed model estimates these parameters in two phases. In first phase the proposed estimates the parameters in two digits after decimal using Algorithm 1. After that the proposed model estimates the third digit after decimal by extending calculated parameters in the first phase by 0.05 in both sides (Algorithm - 2).

Algorithm 1: Estimating each parameter two digits after decimal using proposed SEIR-RGS method 
Let $\beta, \varepsilon$ and $\gamma$ be transmission rate, incubation rate and infection rate respectively. Let $\beta \in[0.10 .5], \varepsilon \in[0.10 .5]$ and $\gamma$ be slope of the equation 2 using least square technique.

Function FindParametersTwoDigistAfterDecimal $(\beta, \varepsilon, \gamma)$

Begin:

For each value $\beta$ in the range between 0.1 and 0.5 with increment value 0.01

Begin:

For each value $\varepsilon$ in the range between 0.1 and 0.5 with increment value 0.01

Solve differential equations 1 with parameter values $(\beta, \varepsilon, \gamma)$ and using initial condition 1

Let $(\mathrm{S}, \mathrm{E}, \mathrm{I}, \mathrm{R})$ be the solution.

Calculate sum of squared distance between estimated $\mathrm{I}$ and $\mathrm{I}_{\mathrm{avg}}$ End For

End For

Let $\left(\beta^{\prime}, \varepsilon^{\prime}\right)$ be the final set of values which having the minimum sum of squared distance with $I_{\text {avg }}$

return $\left(\beta^{\prime}, \varepsilon^{\prime}\right)$

End Function

\section{Algorithm-2: Estimating each parameter third digit after} decimal using proposed SEIR-GS method

Let $\beta$ 'and $\varepsilon$ ' be estimated transmission rate and incubation rate respectively from the Algorithm 1 and $\gamma$ be slope of the equation 2 using least square technique

Function FindParametersThirdDigitAfterDecimal $(\beta, \varepsilon, \gamma)$ Begin:

For each value $\beta$ in the range between $\beta^{\prime}-0.05$ and $\beta^{\prime}+$

0.05 with increment value as 0.001

Begin:

For each value $\varepsilon$ in the range between $\varepsilon^{\prime}-0.05$ and $\varepsilon^{\prime}+$

0.05 with increment value as 0.001

Begin:

Solve differential equations 1 with parameter values $(\beta, \varepsilon, \gamma)$ and using initial condition 1

Let $(\mathrm{S}, \mathrm{E}, \mathrm{I}, \mathrm{R})$ be the solution.

Calculate sum of squared distance between estimated

I and $\mathrm{I}_{\mathrm{avg}}$ End For

\section{End For}

Let $(\beta,, \varepsilon ')$ be the final set of values which having the minimum sum of squared distance with $I_{\text {avg }}$ return $(\beta,, \varepsilon ")$

End Function

Step 4: To estimate infectious period, incubation period and basic reproduction number the present model uses following formulas from the estimated model parameters $\beta, \varepsilon$ and $\gamma$.

Infectious period $=1 / \mathrm{Y}$

Incubation period $=1 / \varepsilon$

Basic reproduction number $(\mathrm{R} 0)=\beta / \gamma$

\section{EXPERIMENT AND RESULT}

The present paper considered the daily covid information of all thirteen districts from 1-2-2-2021 to 18-9-2021. Table 1 shows the total number population, total infections, total recoveries and total deaths during this period and Table 2 shows the infected population percentage, total infected percentage, total recovery percentage all thirteen districts in AP and Fig 3 shows the comparison of all districts.

Table 1. Total number of populations, infections, recoveries, and deaths of each 13 districts of Andhra Pradesh.

\begin{tabular}{|c|c|c|c|c|}
\hline District Name & Population & Infections & Recoveries & Deaths \\
\hline Anantapur & $\mathbf{4 4 2 4 7 8 1}$ & $\mathbf{8 9 8 4 9}$ & $\mathbf{8 9 3 0 8}$ & 493 \\
\hline Chittoor & $\mathbf{4 5 2 5 5 2 0}$ & $\mathbf{1 5 4 8 1 6}$ & $\mathbf{1 5 1 7 4 5}$ & $\mathbf{1 0 3 8}$ \\
\hline East Godavari & $\mathbf{5 5 8 8 2 8 8}$ & $\mathbf{1 6 4 7 3 0}$ & $\mathbf{1 6 2 0 1 1}$ & $\mathbf{6 3 6}$ \\
\hline Guntur & $\mathbf{5 2 9 9 3 6 7}$ & $\mathbf{9 9 1 5 4}$ & $\mathbf{9 7 7 4 4}$ & $\mathbf{5 2 8}$ \\
\hline YSR Kadapa & $\mathbf{2 8 8 2 4 6 9}$ & $\mathbf{5 8 9 1 5}$ & $\mathbf{5 8 2 2 7}$ & 173 \\
\hline Krishna & $\mathbf{4 8 9 7 7 6 3}$ & $\mathbf{6 7 5 3 8}$ & $\mathbf{6 5 4 8 6}$ & $\mathbf{6 7 9}$ \\
\hline Kurnool & $\mathbf{4 3 9 4 7 6 5}$ & $\mathbf{6 3 1 5 0}$ & $\mathbf{6 2 7 9 4}$ & $\mathbf{3 6 3}$ \\
\hline Nellore & $\mathbf{3 2 1 3 0 8 8}$ & $\mathbf{8 1 0 9 8}$ & $\mathbf{7 8 2 6 8}$ & $\mathbf{5 2 2}$ \\
\hline Prakasam & $\mathbf{3 6 8 3 5 1 3}$ & $\mathbf{7 3 6 3 9}$ & $\mathbf{7 0 6 1 1}$ & $\mathbf{5 0 1}$ \\
\hline Srikakulam & $\mathbf{2 9 3 0 7 1 6}$ & $\mathbf{7 6 4 0 7}$ & $\mathbf{7 5 7 6 5}$ & $\mathbf{4 3 4}$ \\
\hline Visakhapatnam & $\mathbf{4 6 5 1 8 5 7}$ & $\mathbf{9 6 3 3 3}$ & $\mathbf{9 5 5 0 4}$ & $\mathbf{5 5 2}$ \\
\hline Vizianagaram & $\mathbf{2 5 4 1 8 7 9}$ & $\mathbf{4 1 5 2 7}$ & $\mathbf{4 0 9 9 7}$ & $\mathbf{4 3 1}$ \\
\hline West Godavari & $\mathbf{4 2 6 8 4 5 9}$ & $\mathbf{8 2 2 9 7}$ & $\mathbf{8 0 6 7 5}$ & $\mathbf{5 5 7}$ \\
\hline Total AP & $\mathbf{9 1 7 0 2 4 7 8}$ & $\mathbf{1 1 4 9 4 5 3}$ & $\mathbf{1 1 2 9 1 3 5}$ & $\mathbf{6 9 0 7}$ \\
\hline
\end{tabular}

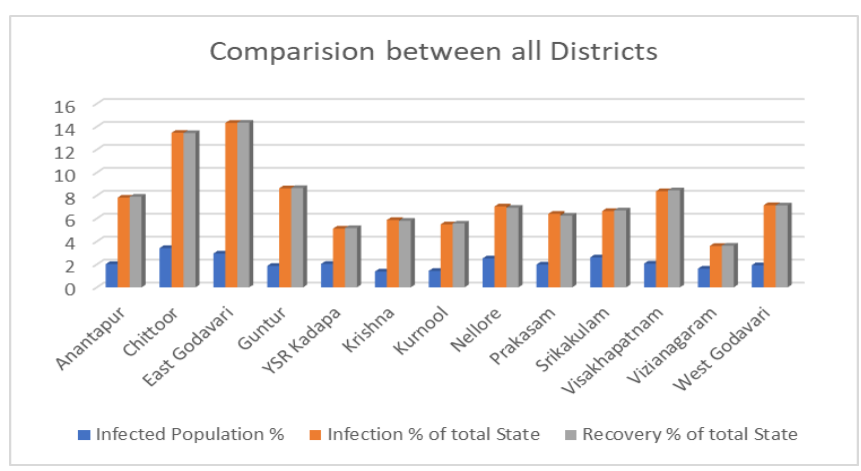

Fig. 3: comparison of all districts

Table 2: Infected population percentage, infection percentage and recovery percentage of all districts in $\mathrm{AP}$

\begin{tabular}{|c|c|c|c|}
\hline District Name & $\begin{array}{c}\text { Infected } \\
\text { Population } \\
\%\end{array}$ & $\begin{array}{c}\text { Infection \% } \\
\text { of total State }\end{array}$ & $\begin{array}{c}\text { Recovery \% of } \\
\text { total State }\end{array}$ \\
\hline Anantapur & 2.03 & 7.82 & 7.9 \\
\hline Chittoor & 3.42 & 13.47 & 13.44 \\
\hline East Godavari & 2.95 & 14.33 & 14.35 \\
\hline Guntur & 1.87 & 8.63 & 8.65 \\
\hline
\end{tabular}


International Journal of Engineering Applied Sciences and Technology, 2021

Vol. 6, Issue 5, ISSN No. 2455-2143, Pages 273-285

Published Online September 2021 in IJEAST (http://www.ijeast.com)

\begin{tabular}{|c|c|c|c|}
\hline YSR Kadapa & $\mathbf{2 . 0 4}$ & 5.12 & 5.16 \\
\hline Krishna & 1.38 & 5.87 & 5.8 \\
\hline Kurnool & 1.44 & 5.49 & 5.56 \\
\hline Nellore & 2.52 & 7.05 & 6.93 \\
\hline Prakasam & 1.99 & 6.41 & 6.25 \\
\hline Srikakulam & 2.61 & 6.65 & 6.71 \\
\hline Visakhapatnam & 2.07 & $\mathbf{8 . 3 8}$ & $\mathbf{8 . 4 6}$ \\
\hline Vizianagaram & 1.63 & 3.61 & 3.63 \\
\hline West Godavari & 1.93 & 7.16 & 7.14 \\
\hline Total AP Cases & 1.25 & 100 & 100 \\
\hline
\end{tabular}

The present SEIR-RGS method estimated that $\beta$ as $0.379, \varepsilon$ as 0.265 and $\gamma$ as 0.098 for entire state AP. So average duration of infectious period as 10.20 days, duration of incubation period as 3.77 days and average basic reproduction $\left(\mathrm{R}_{0}\right)$ as 2.48 for total Andhra Pradesh during second wave i.e., from 12-2021 to 18-9-2021. Table 3 shows the estimated parameters of AP using proposed SEIR-RGS model and Fig 4 shows the daily active cases, confirms vs receives, SEIR-RGS model results and daily confirms vs predicted by proposed SEIRRGS model of AP.

Table 3: Estimated parameters for Andhra Pradesh using proposed method

\begin{tabular}{|c|c|}
\hline Parameter & Value \\
\hline Contact rate & $\mathbf{0 . 2 4 3}$ \\
\hline Infectious period & $\mathbf{1 0 . 2 0}$ days \\
\hline Incubation period & $\mathbf{3 . 7 7}$ days \\
\hline Basic reproduction $\left(\mathbf{R}_{\mathbf{0}}\right)$ & $\mathbf{2 . 4 8}$ \\
\hline
\end{tabular}

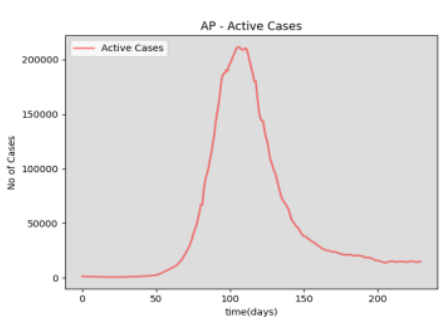

(a)

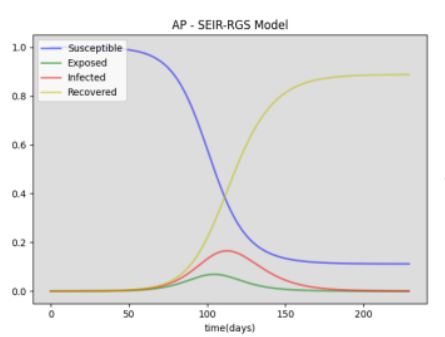

(c)

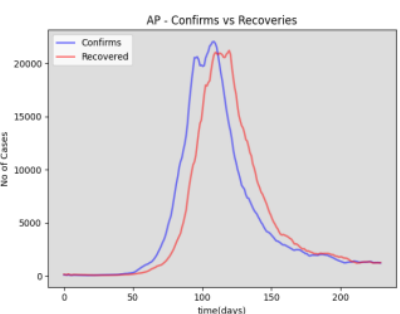

(b)

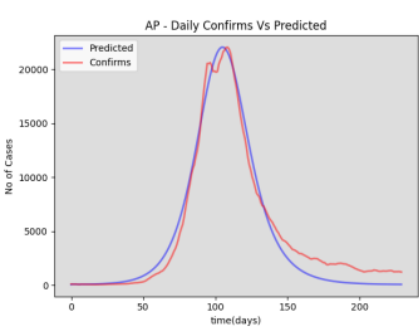

(d)

Fig. 4: Andhra Pradesh (a) daily active cases (b) confirms vs recoveries (c) SEIR-RGS model results (d) daily confirms vs predicted by proposed SEIR-RGS model

Anantapur: Anantapur is one of Rayalaseema region district in the state of AP. As per [31] 89,478 (eighty-nine thousand four hundred and seventy-eight) people infected, 89308(eighty-nine thousand three hundred and eight) people recovered and 493 (four hundred and ninety-three) people died during second wave in this district respectively, nearly $2.03 \%$ people effected with the pandemic out of total population. The present SEIR-RGS method estimated that $\beta$ as $0.476, \varepsilon$ as 0.156 and $\gamma$ as 0.158 . So average duration of infectious period as 6.33 days, duration of incubation period as 6.41 days and average basic reproduction $\left(\mathrm{R}_{0}\right)$ as 3.01. Table 4 shows the estimated parameters using proposed method and Fig 5 shows the SEIR-RGS model results.

Table 4: Estimated parameters for Anantapur district using proposed method

\begin{tabular}{|c|c|}
\hline Parameter & Value \\
\hline Contact rate & $\mathbf{0 . 4 7 6}$ \\
\hline Infectious period & $\mathbf{6 . 3 3}$ days \\
\hline Incubation period & $\mathbf{6 . 4 1}$ days \\
\hline Basic reproduction $\left(\mathbf{R}_{\mathbf{0}}\right)$ & $\mathbf{3 . 0 1}$ \\
\hline
\end{tabular}

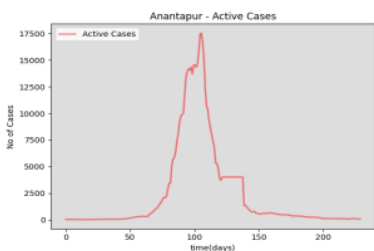

(a)

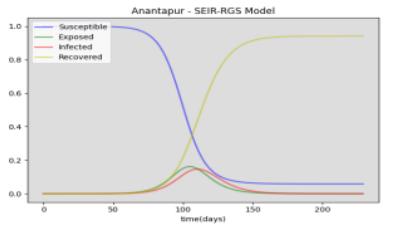

(c)

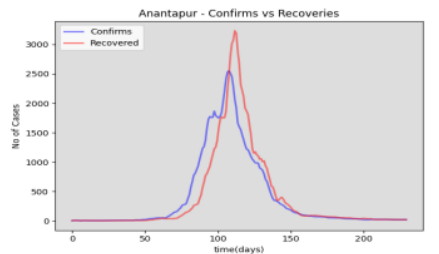

(b)

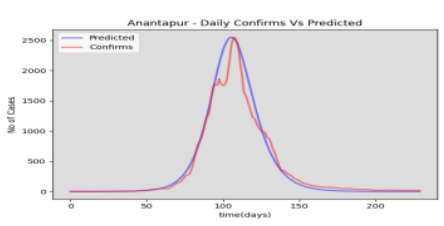

(d)
Fig 5: Anantapur district (a) daily active cases (b) confirms vs recoveries (c) SEIR-RGS model results (d) . daily confirms vs predicted by proposed SEIR-RGS model

Chittoor: Chittoor is southernmost district of AP. It is bordering district with Tamil Nādu state. Its population around 45 lacs [30]. In second wave 1,54,816 (one lac fifty-four thousand eight hundred and sixteen) people infected with covid - 19 but 1,51,745(one lac fifty-one thousand seven hundred and forty-five) $(98.02 \%)$ people recovered as on $18^{\text {th }}$ September. This district recorded highest number of deaths i.e., 1038 (one thousand and thirty-eight) (14.92\%) out of total deaths in AP. As per proposed model, 0.222,0.292 and 0.101 are contact rate, incubation, and recovery rate respectively of this district during second wave. The infectious period of this district as 9.9 days, incubation period as 3.42 days and basic reproduction as 2.19. Table 5 shows the 


\section{International Journal of Engineering Applied Sciences and Technology, 2021 \\ Vol. 6, Issue 5, ISSN No. 2455-2143, Pages 273-285 \\ Published Online September 2021 in IJEAST (http://www.ijeast.com)}

estimated parameter using proposed model and Fig 6 shows the results of proposed SEIR-RGS model.

Table 5: Estimated parameters for Chittoor district using proposed method

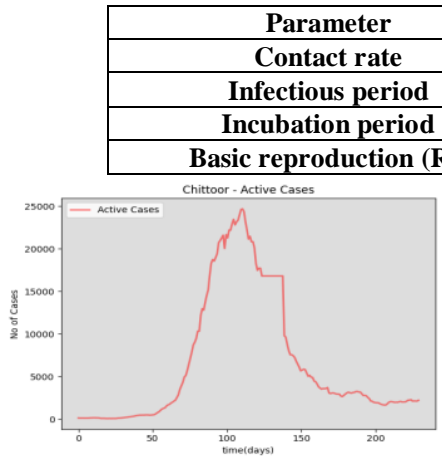

(a)

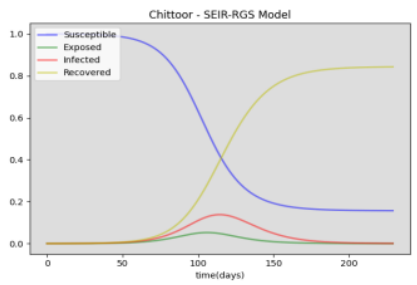

(c)

\begin{tabular}{|c|c|}
\hline & Value \\
\hline & $\mathbf{0 . 2 2 2}$ \\
\hline & $\mathbf{9 . 9}$ days \\
\hline $\left.\mathbf{R}_{0}\right)$ & $\mathbf{3 . 4 2}$ days \\
\hline
\end{tabular}

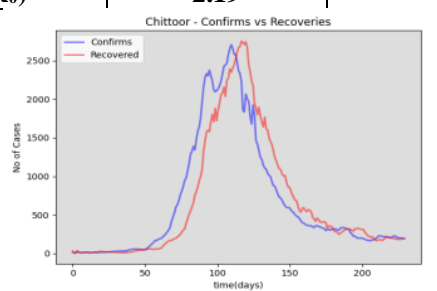

(b)

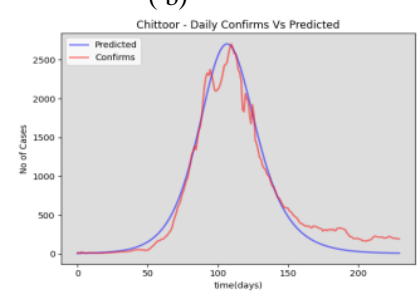

(d)

Fig 6: Chittoor district (a) daily active cases (b) confirms vs recoveries (c) SEIR-RGS model results. (d) daily confirms vs predicted by proposed SEIR-RGS model.

East Godavari: East Godavari is one of highest number of populations out of 13 districts in AP. As per [30] its population nearly 55 lacs. From Andhra Pradesh official daily covid bulletin [31], 1,64,730(one lac sixty-four thousand seven hundred and thirty) people infected from Covid - 19 during second wave i.e., $2.95 \%$ people infected from this pandemic and 1,62,011(one lac sixty-two thousand and eleven) (98.35\%) people recovered from this as on $18^{\text {th }}$ September. The proposed SEIR-RGS method estimated that $\beta$, $\varepsilon$ and $\gamma$ as $0.218,0.459$ and 0.084 respectively. So, on an average one infected person transmits the disease to 4.59 people in the susceptible compartment. The average duration of infectious period $(1 / \gamma)$ of this district as 11.9 days, duration of incubation period $(1 / \varepsilon)$ as 2.18 and average basic reproduction $\left(\mathrm{R}_{0}\right)$ as 2.607. Table 6 shows the estimated parameters and Fig 7 shows the trends of this district.

Table 6: Estimated parameters for East Godavari district using proposed method

\begin{tabular}{|c|c|}
\hline Parameter & Value \\
\hline Contact rate & 0.218 \\
\hline Infectious period & 11.9 days \\
\hline Incubation period & 2.18 days \\
\hline Basic reproduction $\left(\mathbf{R}_{\mathbf{0}}\right)$ & 2.59 \\
\hline
\end{tabular}

Guntur: Guntur is one of coastal district in AP. It is one of bordering district with state of Telangana. According to [30] its population around 53 lacs. In this district totally 99,154 (ninety-nine thousand one hundred and fifty-four) people infected from covid during second wave. Nearly $8.63 \%$ people infected in this district out of total infections in the state of Andhra Pradesh. Out of total infections 97,744 (ninety-seven thousand seven hundred and forty-four) people recovered from covid. Only $1.87 \%$ people infected out of total population in this district. The present model estimated that $\beta$ as 0.243 , $\varepsilon$ as 0.255 and $\gamma$ as 0.096. The average duration of infectious period $(1 / \gamma)$ of this district as 10.41 days, duration of incubation period $(1 / \varepsilon)$ as 3.92 and average basic reproduction $\left(\mathrm{R}_{0}\right)$ as 3.95 . Table 7 and Fig 8 shows the details of proposed SEIR-RGS model.

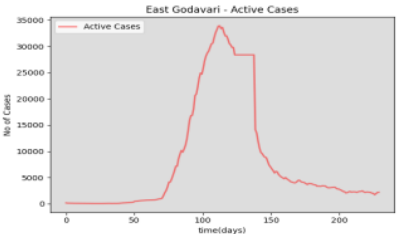

(a)

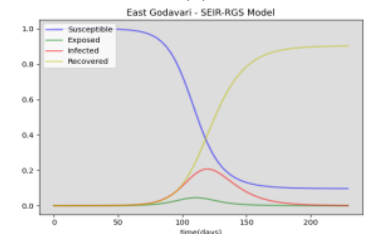

(c)

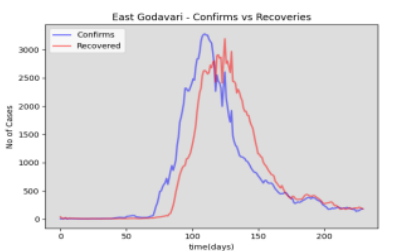

(b)

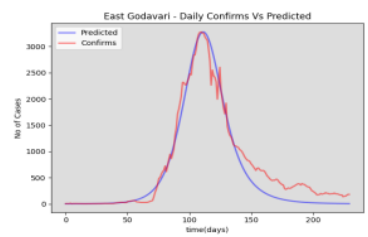

( d)
Fig 7: East Godavari district (a) daily active cases (b) confirms vs recoveries (c) SEIR-RGS model results (d daily confirms vs predicted by proposed SEIR-RGS model.

Table 7: Estimated parameters for Guntur district using proposed method

\begin{tabular}{|c|c|}
\hline Parameter & Value \\
\hline Contact rate & 0.243 \\
\hline Infectious period & 10.41 days \\
\hline Incubation period & $\mathbf{3 . 9 2}$ days \\
\hline Basic reproduction $\left(\mathbf{R}_{\mathbf{0}}\right)$ & $\mathbf{2 . 5 3}$ \\
\hline
\end{tabular}

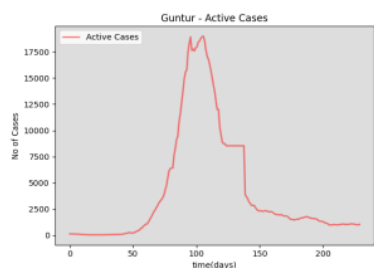

(a)

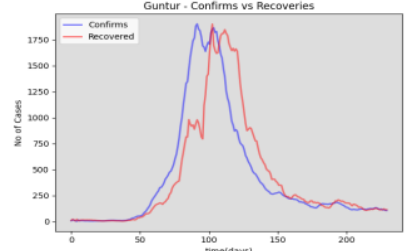

(b) 


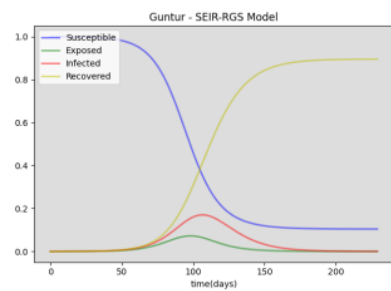

(c)

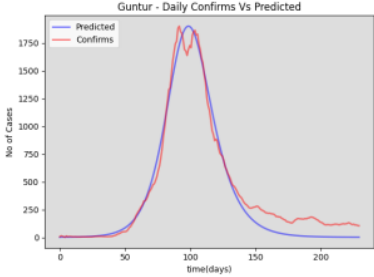

(d)
Fig. 8: Guntur district (a) daily active cases (b) confirms vs recoveries (c) SEIR-RGS model results. (d) daily confirms vs predicted by proposed SEIR-RGS model

YSR Kadapa: Kadapa is centrally located Rayalaseema district in AP. Its population nearly 29 lacs [30]. 58915 (fiftyeight thousand nine hundred and fifteen), 58227(fifty-eight thousand two hundred and twenty-seven) and 173(one hundred and seventy-three) are total number of infected, recovered and deaths people respectively in this district during second wave. The present model estimated that $\beta$ as $0.358, \varepsilon$ as 0.487 and $\gamma$ as 0.139 The average duration of infectious period $(1 / \gamma)$ of this district as 7.19 days, duration of incubation period $(1 / \varepsilon)$ as 2.05 days and average basic reproduction $\left(\mathrm{R}_{0}\right)$ as 2.57 . The proposed model details are shown in Table 8 and Fig 9.

Table 8: Estimated parameters for Kadapa district using proposed method

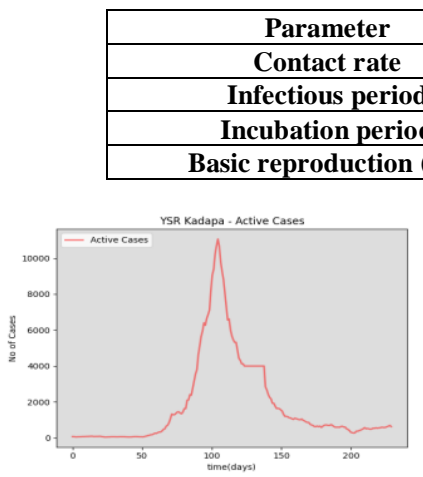

(a)

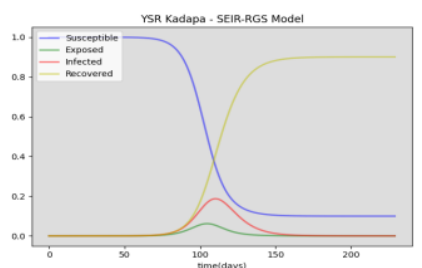

( c )

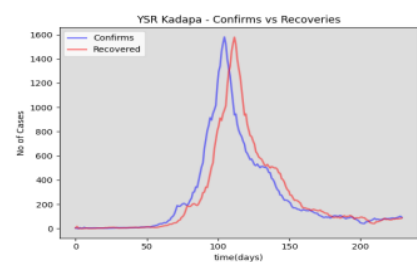

(b)

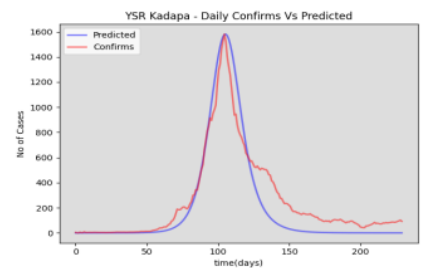

(d)
Fig 9: Kadapa district (a) daily active cases (b) confirms vs recoveries (c) SEIR-RGS model results (d) daily confirms vs predicted by proposed SEIR-RGS model
Krishna: Krishna is one of coastal district in AP. Some of part of this district border with state of Telangana. Its population nearly about 49 lacs [30]. In this district 67538 (sixty-seven thousand five hundred thirty-eight) population effected with covid second wave. But more than $96 \%$ people recovered from this pandemic. Totally 679 (six hundred and seventynine) people lost their life during second wave. The present model estimated that $\beta$ as $0.179, \varepsilon$ as 0.409 and $\gamma$ as 0.076 . The average duration of infectious period $(1 / \gamma)$ of this district as 13.15 days, duration of incubation period $(1 / \varepsilon)$ as 2.44 days and average basic reproduction $\left(\mathrm{R}_{0}\right)$ as 2.35 . Table 8 and Fig 9 shows the details of the proposed SEIR-RGS model.

Table 9: Estimated parameters for Krishna district using proposed method

\begin{tabular}{|c|c|}
\hline Parameter & Value \\
\hline Contact rate & 0.179 \\
\hline Infectious period & 13.15 days \\
\hline Incubation period & 2.44 days \\
\hline Basic reproduction $\left(\mathbf{R}_{\mathbf{0}}\right)$ & $\mathbf{2 . 3 5}$ \\
\hline
\end{tabular}

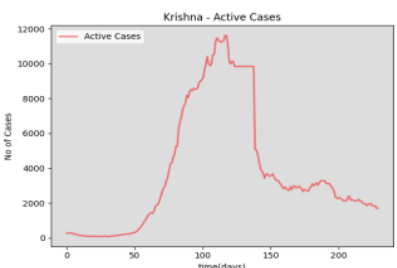

(a)

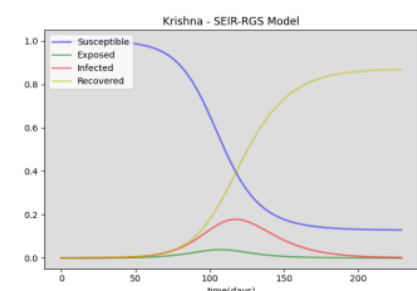

(c)

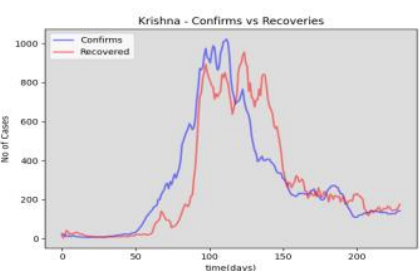

(b)

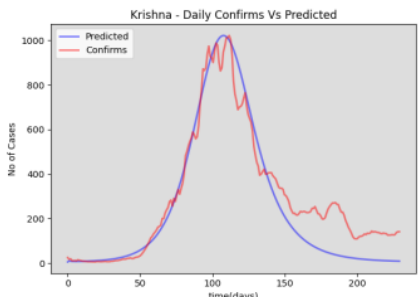

(d)
Fig 10: Krishna district (a) daily active cases (b) confirms vs recoveries (c) SEIR-RGS model results (d) daily confirms vs predicted by proposed SEIR-RGS model

Kurnool: Kurnool was capital of AP between October 1953 and November 1956. It is one of Rayalaseema district out four districts in AP. Its population around 44 lacs according to estimated population 2021[30]. In this district $5.49 \%$ $(63,150)$ effected with covid second wave out of total infections in the state of Andhra Pradesh. $5.56 \%(62,794)$ people recovered out of total recoveries in AP. The present model estimated that $\beta$ as $0.49, \varepsilon$ as 0.134 and $\gamma$ as 0.133 . The average duration of infectious period $(1 / \gamma)$ of this district as 7.52 days, duration of incubation period $(1 / \varepsilon)$ as 7.46 days 


\section{International Journal of Engineering Applied Sciences and Technology, 2021 \\ Vol. 6, Issue 5, ISSN No. 2455-2143, Pages 273-285 \\ Published Online September 2021 in IJEAST (http://www.ijeast.com)}

and average basic reproduction $\left(\mathrm{R}_{0}\right)$ as 3.68. Table 10 and Fig 11 shows the details of the proposed SEIR-RGS of this district.

Table 10: Estimated parameters for Kurnool district using proposed method

\begin{tabular}{|c|c|}
\hline Parameter & Value \\
\hline Contact rate & 0.49 \\
\hline Infectious period & 7.52 days \\
\hline Incubation period & $\mathbf{7 . 4 6}$ days \\
\hline Basic reproduction $\left(\mathbf{R}_{\mathbf{0}}\right)$ & $\mathbf{3 . 6 8}$ \\
\hline
\end{tabular}

Nellore: Nellore is one of southeastern coastal district of AP. Its population around 32 lacs. Totally 81,098(eighty-one thousand ninety-eight) people effected with covid during second wave and 78268 (seventy-eight thousand two hundred and sixty-eight) people recovered with percentage of 6.93 out of total recoveries in AP. But 522 people lost their life. The present model estimated that $\beta$ as 0.209 , $\varepsilon$ as 0.489 and $\gamma$ as 0.071 . The average duration of infectious period $(1 / \gamma)$ of this district as 14.08 days, duration of incubation period $(1 / \varepsilon)$ as 2.04 days and average basic reproduction $\left(\mathrm{R}_{0}\right)$ as 2.94 . The

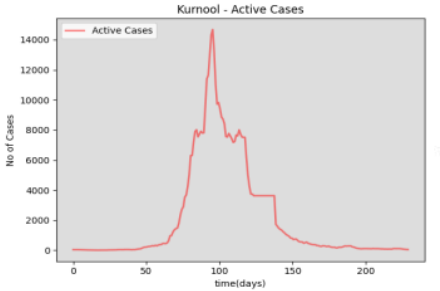

(a)

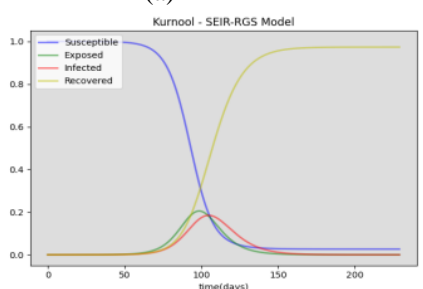

(c)

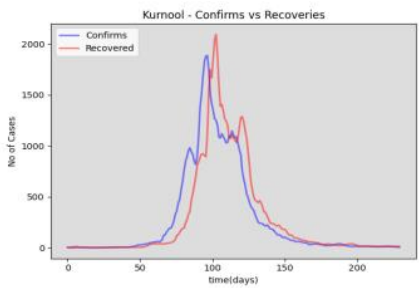

(b)

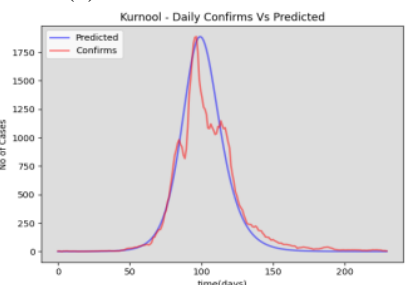

(d)
Fig 11: Kurnool district (a) daily active cases (b) confirms vs recoveries (c) SEIR-RGS model results (d) daily confirms vs predicted by proposed SEIR-RGS model

details of the proposed SEIR-RGS shown in Table 11 and Fig 12

Table 11: Estimated parameters for Nellore district using proposed method

\begin{tabular}{|c|c|}
\hline Parameter & Value \\
\hline Contact rate & 0.209 \\
\hline Infectious period & 14.08 days \\
\hline Incubation period & $\mathbf{2 . 0 4}$ days \\
\hline Basic reproduction $\left(\mathbf{R}_{0}\right)$ & 2.94 \\
\hline
\end{tabular}

Prakasam: Prakasam is third largest and one of coastal region district in the state of AP. The estimated population in this district around nearly 37 lacs [30] (according to 2021 estimation). During second wave 73639(seventy-three thousand six hundred and thirty-nine) people in this district effected with covid with percentage of 6.41out of total infections in AP. Only $1.99 \%$ people effected out of total population in this district. The present model estimated that $\beta$ as $0.188, \varepsilon$ as 0.429 and $\gamma$ as 0.056 . The average duration of infectious period $(1 / \gamma)$ of this district as 17.85 days, duration of incubation period $(1 / \varepsilon)$ as 2.33 days and average basic reproduction $\left(\mathrm{R}_{0}\right)$ as 3.35 . More details shown in Table 12 and Fig 13.

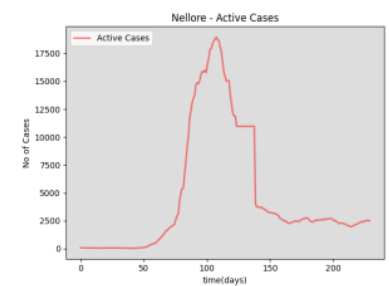

(a)

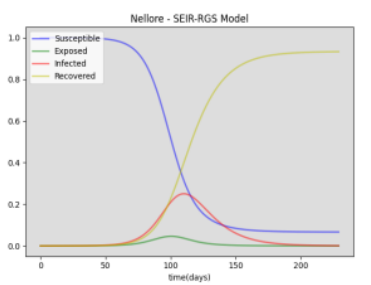

(c)

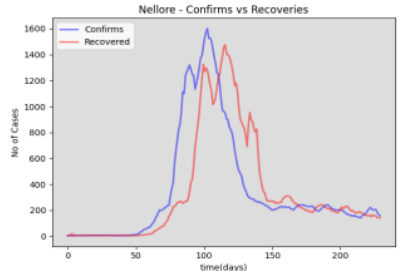

(b)

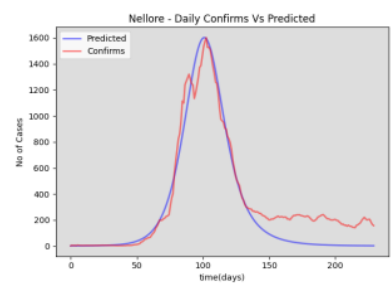

(d)
Fig 12: Nellore district (a) daily active cases (b) confirms vs recoveries (c) SEIR-RGS model results (d) daily confirms vs predicted by proposed SEIR-RGS model

Table 12: Estimated parameters for Prakasam district using proposed method

\begin{tabular}{|c|c|}
\hline Parameter & Value \\
\hline Contact rate & 0.188 \\
\hline Infectious period & 17.85 days \\
\hline Incubation period & 2.33 days \\
\hline Basic reproduction $\left(\mathbf{R}_{\mathbf{0}}\right)$ & $\mathbf{3 . 3 5}$ \\
\hline
\end{tabular}

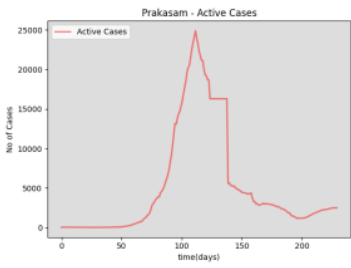

(a)

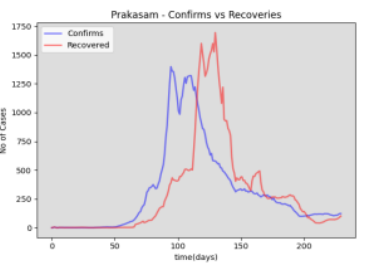

(b) 


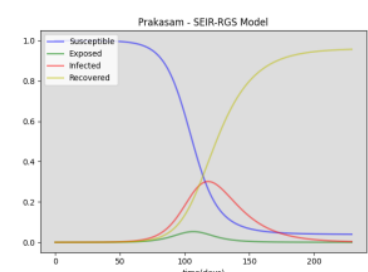

(c)

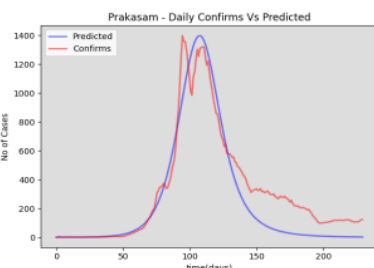

(d)
Fig 13: Prakasam district (a) daily active cases (b) confirms vs recoveries (c) SEIR-RGS model results (d) daily confirms vs predicted by proposed SEIR-RGS model

Srikakulam: Srikakulam is one of coastal region district out of 9 districts in AP. The population of this district around 29 lacs according to estimated population 2021[30]. In this district totally 76,407(seventy-six thousand four hundred and seven) people suffered from covid during second wave i.e., $6.65 \%$ infections out of total infections and 434 people lot their life during second wave. The present model estimated that $\beta$ as $0.399, \varepsilon$ as 0.121 and $\gamma$ as 0.092 . The average duration of infectious period $(1 / \gamma)$ of this district as 10.87 days, duration of incubation period $(1 / \varepsilon)$ as 8.26 days and average basic reproduction $\left(\mathrm{R}_{0}\right)$ as 4.33 . Table 13 and Fig 14 shows results of proposed SEIR-RGS model results.

Table 13: Estimated parameters for Srikakulam district using proposed method

\begin{tabular}{|c|c|}
\hline Parameter & Value \\
\hline Contact rate & 0.399 \\
\hline Infectious period & 10.87 days \\
\hline Incubation period & $\mathbf{8 . 2 6}$ days \\
\hline Basic reproduction $\left(\mathbf{R}_{\mathbf{0}}\right)$ & 4.33 \\
\hline
\end{tabular}

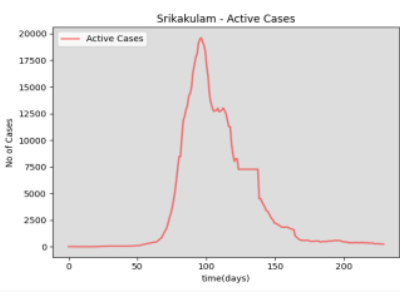

(a)

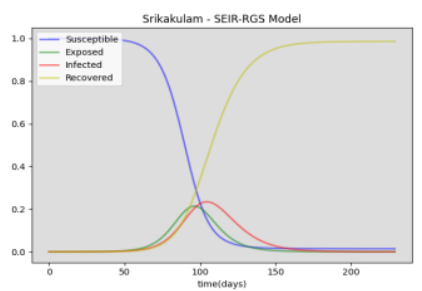

(c)

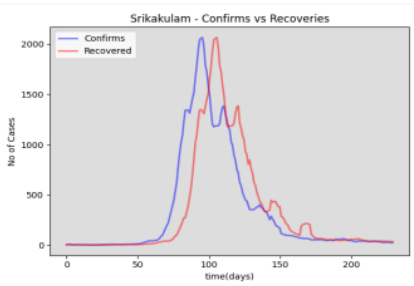

(b)

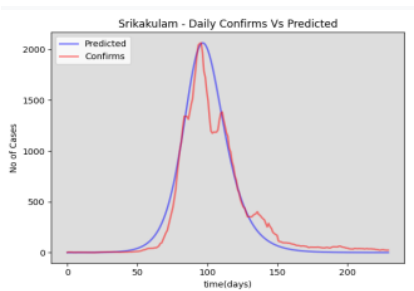

(d)
Fig 14: Srikakulam district (a) daily active cases (b) confirms vs recoveries (c) SEIR-RGS model results (d) daily confirms vs predicted by proposed SEIR-RGS model
Visakhapatnam: Visakhapatnam comes under Uttar Andhra region coastal district in AP. Its population around 46 lacs [30]. It is economical capital AP. In second wave 96333(ninety-six thousand three hundred and thirty-three) people infected from covid. 95,504(ninety-five thousand five hundred and four) (99.14\%) people recovered from this pandemic. The present model estimated that $\beta$ as $0.259, \varepsilon$ as 0.352 and $\gamma$ as 0.099 . The average duration of infectious period $(1 / \gamma)$ of this district as 10.10 days, duration of incubation period $(1 / \varepsilon)$ as 2.84 days and average basic reproduction $\left(\mathrm{R}_{0}\right)$ as 2.61. Table 14 and Fig 14 shows the details of proposed SEIR-RGS model.

Table 14: Estimated parameters for Visakhapatnam district using proposed method

\begin{tabular}{|c|c|}
\hline Parameter & Value \\
\hline Contact rate & 0.259 \\
\hline Infectious period & $\mathbf{1 0 . 1 0}$ days \\
\hline Incubation period & $\mathbf{2 . 8 4}$ days \\
\hline Basic reproduction $\left(\mathbf{R}_{\mathbf{0}}\right)$ & $\mathbf{2 . 6 1}$ \\
\hline
\end{tabular}

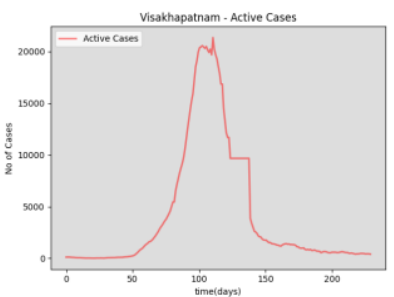

(a)

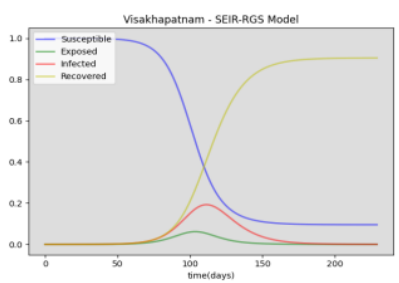

(c)

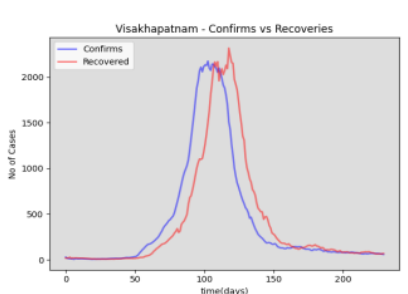

(b)

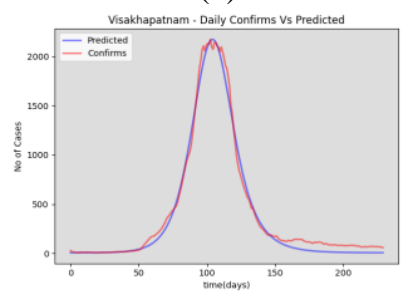

(d)

Fig 15: Visakhapatnam district (a) daily active cases (b) confirms vs recoveries (c) SEIR-RGS model results (d) daily confirms vs predicted by proposed SEIR-RGS model

Vizianagaram: Vizianagaram is one of coastal district out 13 districts in AP. It is also bordering district of Orissa state. Its population around 25 lacs [30]. Totally $3.61 \% \quad(41,527)$ people infected with covid out of total infections in AP. $98.72 \%(40,997)$ people recovered from this district. The present model estimated that $\beta$ as 0.259 , $\varepsilon$ as 0.478 and $\gamma$ as 0.100 The average duration of infectious period $(1 / \gamma)$ of this district as 10 days, duration of incubation period (1/ 1 ) as 2.09 days and average basic reproduction $\left(\mathrm{R}_{0}\right)$ as 2.59 . Table 15 and Fig 16 shows the details of the proposed SEIR-RGS model. 
Table 15: Estimated parameters for Vizianagaram district using proposed method

\begin{tabular}{|c|c|}
\hline Parameter & Value \\
\hline Contact rate & 0.259 \\
\hline Infectious period & 10 days \\
\hline Incubation period & $\mathbf{2 . 0 9}$ days \\
\hline Basic reproduction $\left(\mathbf{R}_{0}\right)$ & 2.59 \\
\hline
\end{tabular}

West Godavari: West Godavari is one of coastal district out of 13 districts in AP. Its population nearly 43 lacs according to estimated population in 2021 [31]. 82,297 (eighty-two thousand two hundred ninety-seven) people infected from covid during second wave in this district. 98.03\% (80675) people recovered in this district out of total recoveries in AP. The present model estimated that $\beta$ as $0.260, \varepsilon$ as 0.499 and $\gamma$ as 0.098 The average duration of infectious period $(1 / \gamma)$ of this district as 10.20 days, duration of incubation period $(1 / \varepsilon)$ as 2.00 days and average basic reproduction $\left(\mathrm{R}_{0}\right)$ as 2.65 . More details about this district given in Table and Fig using proposed SEIR-RGS model.

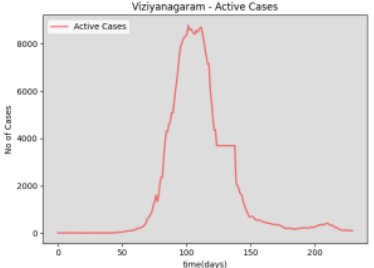

(a)

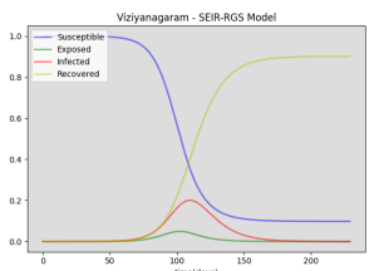

(c)

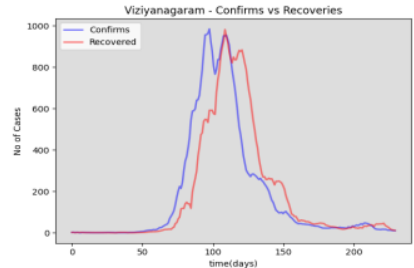

(b)

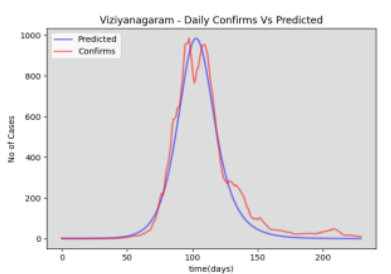

(d)
Fig 16: Vizianagaram district (a) daily active cases (b) confirms vs recoveries (c) SEIR-RGS model results (d) daily confirms vs predicted by proposed SEIR-RGS model

Table 16: Estimated parameters for West Godavari district using proposed method

\begin{tabular}{|c|c|}
\hline Parameter & Value \\
\hline Contact rate & $\mathbf{0 . 2 6 0}$ \\
\hline Infectious period & $\mathbf{1 0 . 2 0}$ days \\
\hline Incubation period & $\mathbf{2 . 0 0}$ days \\
\hline Basic reproduction $\left(\mathbf{R}_{\mathbf{0}}\right)$ & $\mathbf{2 . 6 5}$ \\
\hline
\end{tabular}

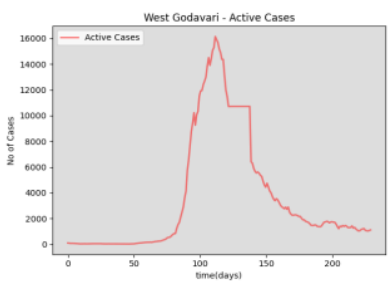

(a)

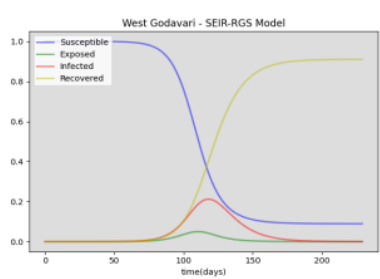

(c)

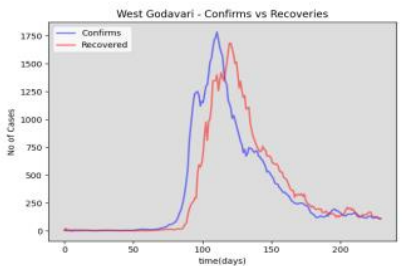

(b)

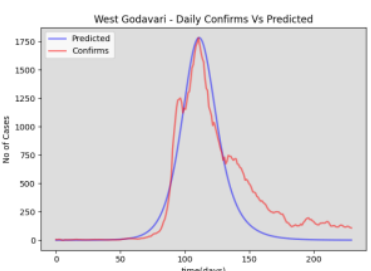

(d)
Fig 17: West Godavari district (a) daily active cases (b) confirms vs recoveries (c) SEIR-RGS model results (d) daily confirms vs predicted by proposed SEIR-RGS model

Table 17 shows the estimated parameters using proposed SEIR-RGS model of all thirteen districts of AP. Fig 18, Fig 19 and Fig 20 shows the comparison of all thirteen districts infectious period and incubation period, contact rate and basic reproduction number respectively.

Table 17 Estimated model parameters all thirteen districts of Andhra Pradesh

\begin{tabular}{|c|c|c|c|c|}
\hline District & $\begin{array}{c}\text { Contact } \\
\text { rate }\end{array}$ & $\begin{array}{c}\text { Infectious } \\
\text { period (in } \\
\text { days) }\end{array}$ & $\begin{array}{c}\text { Incubation } \\
\text { period (in } \\
\text { days) }\end{array}$ & $\begin{array}{c}\text { Basic } \\
\text { reproduction } \\
\text { number }\left(\mathbf{R}_{0}\right)\end{array}$ \\
\hline Anantapur & 0.476 & 6.33 & 6.41 & 3.01 \\
\hline Chittoor & 0.222 & 9.90 & 3.42 & 2.19 \\
\hline East Godavari & 0.219 & 11.90 & 2.23 & 2.61 \\
\hline Guntur & 0.243 & 10.41 & 3.92 & 2.53 \\
\hline YSR Kadapa & 0.358 & 7.19 & 2.05 & 2.57 \\
\hline Krishna & 0.179 & 13.15 & 2.44 & 2.35 \\
\hline Kurnool & 0.490 & 7.52 & 7.46 & 3.68 \\
\hline Nellore & 0.209 & 14.08 & 2.04 & 2.94 \\
\hline Prakasam & 0.188 & $\mathbf{1 7 . 8 5}$ & 2.33 & 3.35 \\
\hline Srikakulam & 0.399 & 10.87 & 8.26 & 4.33 \\
\hline Visakhapatnam & 0.259 & 10.10 & 2.84 & 2.61 \\
\hline Vizianagaram & 0.259 & 10.00 & 2.09 & 2.59 \\
\hline West Godavari & 0.260 & 10.20 & 2.00 & 2.65 \\
\hline AP & 0.243 & 10.20 & 3.77 & 2.48 \\
\hline
\end{tabular}


Comparision of all districts - infectious period and incubation period (in days)

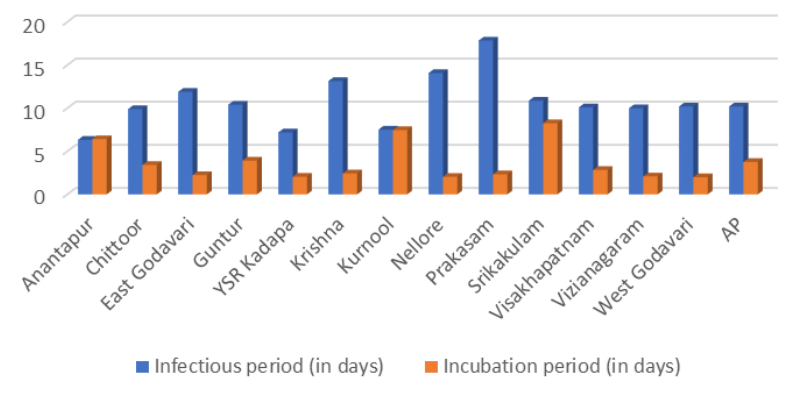

Fig 18 Comparison of all districts infectious period and incubation period

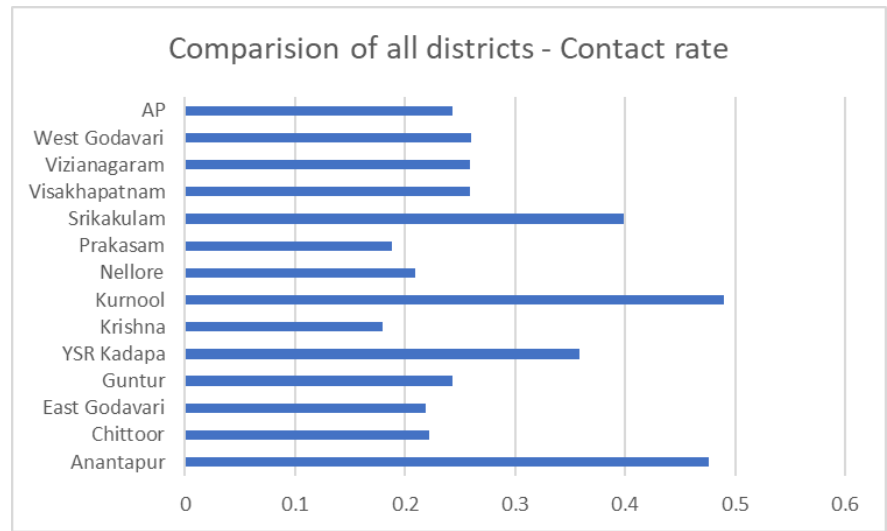

Fig 18 Comparison of all districts contact rate

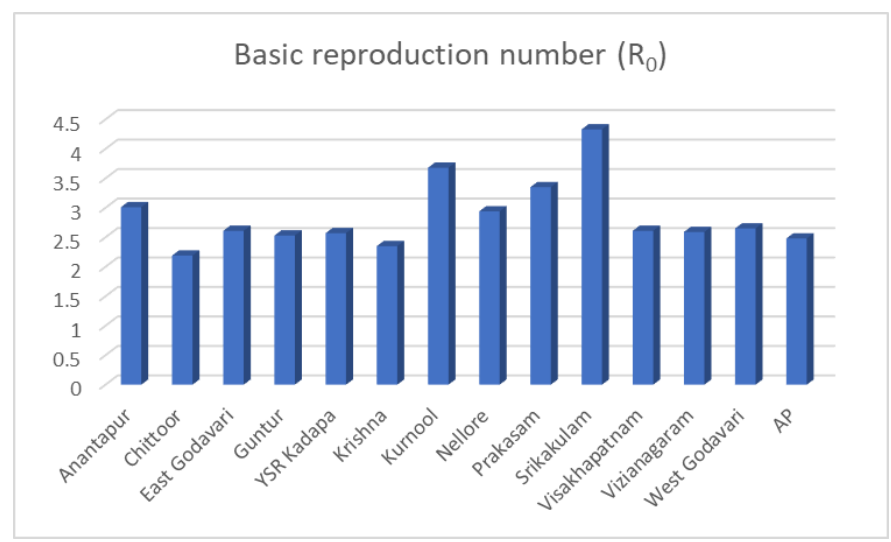

Fig 19 Comparison of all districts basic reproduction number $\left(\mathrm{R}_{0}\right)$

\section{Discussion:}

The proposed SEIR-RGS model estimated that the average infectious period of entire state is 10.20. The infectious period in Anantapur, Chittoor, YSR Kadapa, Kurnool, Visakhapatnam and Vizianagaram less than infectious period of entire state. But in East Godavari, Guntur, Krishna, Nellore, Prakasam and Srikakulam infectious period more than entire state of Andhra Pradesh. In West Godavari district the infectious period exactly equal to total state of AP. Out of 13 districts the infectious period in Prakasam very high i.e., 17.85 days compare to remaining districts. That is the reason Prakasam district has more number of active cases even though less number of infections (only 6.35\%) compare to Chittoor (13.42\%) , East Godavari (14.33\%) etc. The infectious period in Anantapur very less i.e., 6.33 days comparative to remaining all 12 districts. That is the reason in this district active infections very less i.e., only 95. Similarly in East Godavari, Krishna and Nellore recorded more active infections 2264, 2138 and 2056 respectively because of more infectious period than remaining districts.

From the estimated results we can observe that the proposed model SEIR-RGS model calculated average incubation period for entire state as 3.77 days. In both Godavari districts, YSR Kadapa, Krishna, Nellore, Prakasam, Visakhapatnam and Vizianagaram incubation period very less than average incubation period of total AP. Srikakulam districts has highest incubation period (8.26 days) than remaining all districts. Kurnool estimated second highest incubation period (7.46 days). In both Anantapur and Kurnool the average infectious period and incubation period almost same. These two districts come under Rayalaseema region and both are neighboring districts.

From experimental results we can observe that the basic reproduction number (R0) very high i.e., 4.99 in Srikakulam district comparative to remaining all districts. In this district people mainly prefer either government job or migrate to other places in pan India for better employment or livelihood. Initially in two waves very few cases noted but slowly increased than expected. Especially happened after lockdowns in different places in India. The basic reproduction number is greater than 2 for all districts. So, one person infected at least two persons in this state. As per Table 17 we can observe that the basic reproduction number for Anantapur, Kurnool, Prakasam also more than three. In Visakhapatnam and Vizianagaram infectious period, incubation period and basic reproduction number almost similar. Both districts come under Utter Andhra region, and both are neighboring districts. Also, in both Godavari districts basic reproduction number almost same.

The real data and predicted values from proposed model i.e., SEIR-RGS almost same for the districts Anantapur, Kurnool, Srikakulam, Visakhapatnam and Vizianagaram. Therefore, situation becoming normal for these districts. There are chances of third wave if any new mutations come into picture. But we observed that small deviation between real and predicted value in the right tail for remaining districts especially after August second week. So still situation not in good control for these districts. To become normal, we need to implement covid protocols very strictly in these districts otherwise may leads to third wave in these districts. 


\section{International Journal of Engineering Applied Sciences and Technology, 2021 \\ Vol. 6, Issue 5, ISSN No. 2455-2143, Pages 273-285 \\ Published Online September 2021 in IJEAST (http://www.ijeast.com)}

\section{CONCLUSION}

This paper introduces SEIR - RGS model for estimating contact rate, incubation rate and recovery rate of 13 districts of AP. The proposed model collects daily covid information from Department of Health and family from first February 2021 to $18^{\text {th }}$ September 2021. This model estimates the recovery rate of each district using least square method and calculates the remaining two parameters using grid search mechanism in two phases. From the calculated values the proposed model compares infectious period, incubation period and basic reproduction of covid transmission among people of AP district wise. From the results we can conclude that Anantapur, Kurnool, Srikakulam, Visakhapatnam and Vizianagaram are in stable condition, but remaining districts require strict implementation of covid protocols for reducing chances of third wave.

\section{REFERENCE}

[1] Manindra Agrawal, Madhuri Kanitkar and athukumalli Vidyasagar," SUTRA: An Approach to Modelling Pandemics with Asymptomatic Patients,and Applications to COVID-19", arXiv:2101.09158v2 [qbio.PE] 30 Jan 2021

[2] Gaurav Goswamia , Jayanti Prasadb, and Mansi Dhuriac," "Extracting the effective contact rate of COVID-19 pandemic", arXiv:2004.07750v1 [q-bio.PE] 16 Apr 2020

[3] Santosh Ansumali a , Shaurya Kaushal a , Aloke Kumar b , Meher K. Prakash a , M. Vidyasagar," Modelling a pandemic with asymptomatic patients, impact of lockdown and herd immunity, with applications to SARS-CoV-2",Annual Reviews in Control, Volume 50, 2020, Pages 432-447

[4] Taarak Rapolu 1, Brahmani Nutakki2 , T. Sobha Rani3 , S. Durga Bhavani," A Time-Dependent SEIRD Model for Forecasting the COVID-19 Transmission Dynamics", medRxiv preprint doi: https://doi.org/10.1101/2020.05.29.20113571; this version posted June 2, 2020.

[5] Yang Liu, Li-Meng Yan, Lagen Wan, et al. Viral dynamics in mild and severe cases of COVID19. The Lancet, 20(6):656-657, June 2020.

[6] Herbert W. Hethcote. The mathematics of infectious diseases. SIAM Review, 42(4):399-453, 2000

[7] William Ogilvy Kermack and A. G. McKendrick. A contribution to the mathematical theory of epidemics. Proceedings of The Royal Society A, 117(772):700721,1927

[8] Indian Supermodel for Covid-19 Pandemic, National Supermodel Committee

[9] Samuel Mwalili,.Mark Kimathi,2 Viona Ojiambo,1 Duncan Gathungu,1 and Rachel Mbogo," SEIR model for COVID-19 dynamics incorporating the environment and social distancing"

[10] Bogdan Marincaa, Vasile Marinca, Ciprian Bogdancd, "Dynamics of SEIR epidemic model by optimal auxiliary functions method",Chaos, Solitons \& Fractals, Volume 147, June 2021, 110949

[11] Suwardi Annas, Muh.Isbar Pratama ,Muh.Rifandi ,Wahidah Sanusi, Syafruddin Side,"Stability analysis and numerical simulation of SEIR model for pandemic COVID-19 spread in Indonesia",Chaos, Solitons \& Fractals, Volume 139, October 2020

[12] Subrata Paul, Animesh Mahata , Uttam Ghosh ,Banamali Roy,"Study of SEIR epidemic model and scenario analysis of COVID-19 pandemic",Ecological Genetics and Genomics, Volume 19, May 2021

[13] Nidhal ben Khedher ,Lioua Kolsi ,Haitham Alsaif,"A multi-stage SEIR model to predict the potential of a new COVID-19 wave in KSA after lifting all travel restrictions",Alexandria Engineering Journal,Volume 60, Issue 4, August 2021, Pages 3965-3974

[14] Nicola Piovella,"Analytical solution of SEIR model describing the free spread of the COVID-19 pandemic",Chaos, Solitons \& Fractals,Volume 140, November 2020

[15] Steven J.Weinstein,Morgan S.Holland, Kelly, E.Rogers, Nathaniel S.Barlow,"Analytic solution of the SEIR epidemic model via asymptotic approximant",Physica D: Nonlinear Phenomena,Volume 411, October 2020

[16] Zhifang Liao , Peng Lan, Xiaoping Fan ,Benjamin Kelly,Aidan Innes,Zhining Liao,"SIRVD-DL: A COVID-19 deep learning prediction model based on time-dependent SIRVD",Computers in Biology and Medicine,Available online 13 September 2021, 104868

[17] Xinhe Zhu, Bingbing Gao, Yongmin Zhong, Chengfan Gu,Kup-SzeChoic,"Extended Kalman filter based on stochastic epidemiological model for COVID-19 modelling",Computers in Biology and Medicine,Volume 137, October 2021, 104810

[18] Kanu Goel, Shefali Arora," NOVEL CORONAVIRUS (2019-NCOV): IMPACT OF GLOBAL PANDEMIC AND PREDICTIVE ANALYSIS USING MACHINE LEARNING", International Journal of Engineering Applied Sciences and Technology, 2020 Vol. 5, Issue 3, ISSN No. 2455-2143, Pages 368-376

[19] Niteesh Kumar, Harendra Kumar,"A novel hybrid fuzzy time series model for prediction of COVID-19 infected cases and deaths in India",ISA Transactions, Available online 6 July 2021

[20] VeronikaGrimm,, Friederike Mengel \& Martin Schmidt,"Extensions of the SEIR model for the analysis of tailored social distancing and tracing approaches to cope with COVID-19",Scientifc Reports , (2021) 11:4214,https://doi.org/10.1038/s41598-021- 


\section{International Journal of Engineering Applied Sciences and Technology, 2021 \\ Vol. 6, Issue 5, ISSN No. 2455-2143, Pages 273-285 \\ Published Online September 2021 in IJEAST (http://www.ijeast.com)}

83540-2

[21] Shuo Feng, Zebang Feng, Chen Ling, Chen Chang,Zhongke Feng,"Prediction of the COVID-19 epidemic trends based on SEIR and AI models", https://doi.org/10.1371/journal.pone.0245101 January 8, 2021

[22] Syafruddin s.,M. S. M. Noorani,"SEIR model for transmission of dengue fever in Selangor malaysia",International Conference Mathematical and Computational Biology 2011,International Journal of Modern Physics: Conference Series, Vol. 9 (2012) 380389

[23] Hamdy M. Youssef,Najat A. Alghamdi, Magdy A. Ezzat, Alaa A. El-Bary and Ahmed M.Shawky,"A new dynamical modeling SEIR with global analysis applied to the real data of spreading COVID-19 in Saudi Arabia", Mathematical Biosciences and Engineering, MBE, 17(6): 7018-7044.DOI: 10.3934/mbe.2020362,Published: 16 October 2020

[24] Manuel De la Sen, Asier Ibeas, "On an Sir Epidemic Model for the COVID-19 Pandemic and the Logistic Equation", Discrete Dynamics in Nature and Society, vol. 2020, Article ID 1382870, 17 pages, 2020. https://doi.org/10.1155/2020/1382870

[25] Saad Awadh Alanazi, M. M. Kamruzzaman, Madallah Alruwaili, Nasser Alshammari, Salman Ali Alqahtani, Ali Karime, "Measuring and Preventing COVID-19 Using the SIR Model and Machine Learning in Smart Health Care", Journal of Healthcare Engineering, vol. 2020, Article ID 8857346, 12 pages, 2020. https://doi.org/10.1155/2020/8857346

[26] Ian Cooper, Argha Mondal, Chris G. Antonopoulos,"A SIR model assumption for the spread of COVID-19 in different communities",Chaos, Solitons and Fractals 139 (2020) ,Nonlinear Science, and Nonequilibrium and Complex Phenomena

[27] Said Gounane, Yassir Barkouch, Abdelghafour Atlas, Mostafa Bendahmane,Fahd Karami and Driss Meskine,"An adaptive social distancing SIR model for COVID-19 disease spreading and forecasting",Epidemiol. Methods 2021; 10(s1): 20200044

[28] Congying Liu ,Xiaoqun Wu , Riuwu Niu ,Xiuqi Wu , Ruguo Fan,"A new SAIR model on complex networks for analysing the 2019 novel coronavirus (COVID19)",https://doi.org/10.1007/s11071-020-05704-5,(C) Springer Nature B.V. 2020

[29] Liu Ying, Tang Xiaoqing,"COVID-19: Is it safe now? Study of asymptomatic infection spread and quantity risk based on SAIR model",Chaos, Solitons \& Fractals: X,Volume 6, June 2021, 100060

[30] https://www.indiacensus.net/states/andhra-pradesh

[31] https://hmfw.ap.gov.in/covid 19 dailybulletins.aspx
[32] https://www.coronatracker.com/country/india/

[33] Mslb. Subrahmanyam, V. Vijaya Kumar , B. Eswara Reddy," A novel method for segmenting and straightening of text lines in handwritten Telugu documents based on smearing and regression approach", International Journal of Engineering \& Technology, 7 (3) (2018) 1846-1853

[34] Kanika Bhalla, Ashish Kumar," A COMPARATIVE ANALYSIS OF COVID-19 BETWEEN INDIA AND OTHERS USING DATA MINING AND MACHINE LEARNING APPROACH', International Journal of Engineering Applied Sciences and Technology, 2020 Vol. 5, Issue 8, ISSN No. 2455-2143, Pages 102-110

[35] Buddavarapu Teja Swaroop," EVALUATING COVID-19 HEALTH INFORMATION USING MACHINE LEARNING", International Journal of Engineering Applied Sciences and Technology, 2020 Vol. 5, Issue 5, ISSN No. 2455-2143, Pages 302-307

[36] Alavikunhu Panthakkan ,S.M.Anzar ,Saeed Al Mansoori, Hussain AlAhmad,"A novel DeepNet model for the efficient detection of COVID-19 for symptomatic patients",Biomedical Signal Processing and Control,Volume 68, July 2021, 102812 